\title{
Doing, when there is nothing to be done
}

$\mathrm{T}$

his morning's round in the overcrowded department of medicine of an academic hospital moved wearily to the next patient. Twenty new patients were admitted yesterday to our theoretical 35 beds, greatly exceeding once again our maximum capacity. It was past noontime and the team was beginning to show restlessness. We still had a few patients left to examine and ahead loomed the necessity of composing discharge summaries for as many patients as possible in preparation for the next wave of admissions. A quick lunch and a well-deserved break seemed miles away. The next patient however, promised to be an easy one.

He was an elderly gentleman breathing heavily under a large oxygen mask. According to the records, the patient suffered from biopsy-proven idiopathic pulmonary fibrosis that was resistant to all treatments. It took seconds to see that there were no modifiable factors: no superimposed infection, no anemia, no heart failure and not even a suspicion of pulmonary embolism. Just the slow, gradual inevitable and painful decline of the patient's interstitial lung disease.

In short, there was nothing to be done.

I could just briefly pat his hand and escape to the next patient.

Neither the patient nor his son, who rarely left his side, expected anything else.

The temptation to do so was strong. But I knew better. As faculty, I was entitled to sabbaticals and was fortunate to have spent them at Stanford, Harvard and then, Cambridge. They widened my perspective and allowed me time to think. My most memorable discovery was that the outstanding achievements of modern medicine involved mostly the biology of disease and were very likely to continue. However, in sensing the patient's narrative and grief, in support and empathy, in sincere attention to the patient as a person and to the patient's preferences and

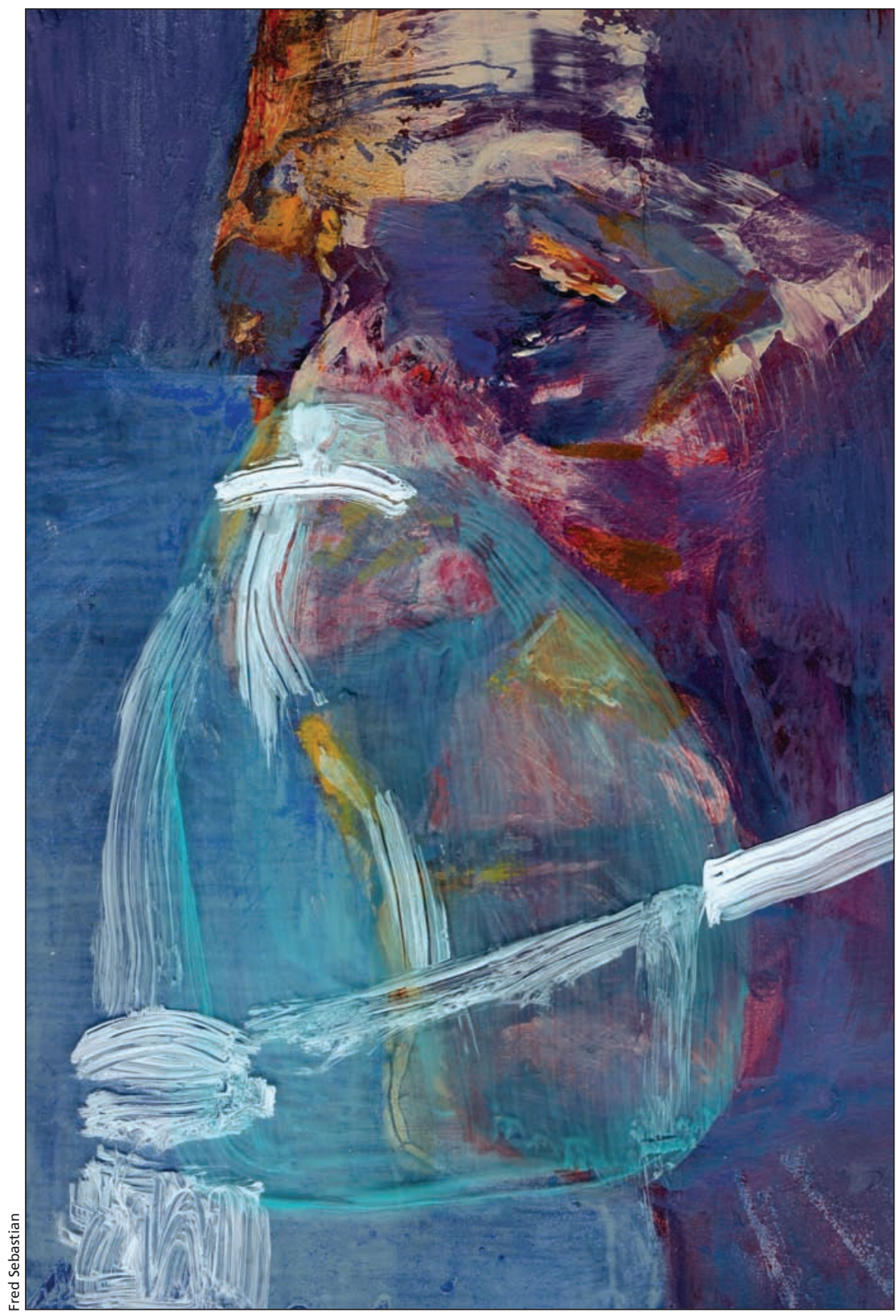

autonomy — we have lagged appallingly behind. I became determined to stress those quintessential approaches in my teaching and research. Now I felt compelled to stay by my patient, no matter how little I could do to affect the biology of his end-stage lung disease.

When I had left his bedside just five minutes later, there was no mistake in his changed bearing, his gleaming eyes. All I did was ask, show real interest and listen. He told me how he 
had to start working manually, barely out of his teens, to support his widowed mother and little brothers. How he rose from the ranks to become the executive of 500 men building roads in Africa. How the disease struck him when he had so many plans still unfulfilled. The despair, but also the small pleasures the attention of his family provided.

When I later met his son, those personal minutes proved invaluable as we planned together the next phase in his father's care. We both felt that it was best done at his home and worked out ways to make that possible. Whenever I saw this patient in the coming days until he stabilized and could be discharged, we always had a warm smile for each other. A bond had been made.
I felt I was doing my duty by this patient and hoped my residents and interns, harassed as they may be now, would grasp the principle and follow my example some time in the future.

I have no way of knowing if they would.

But the long letter I got from the patient's son, months after his discharge home and eventual demise, was no mere formality.

It told me that much can be done, even when there is nothing to do.

\section{Ami Schattner MD \\ Faculty of Medicine \\ Hebrew University and \\ Hadassah Medical School \\ Jerusalem, Israel}

CMAJ 2011. DOI:10.1503/cmaj.100610

\section{More Humanities at www.cmaj.ca}

\section{Books}

Care of the Soul in Medicine: Healing Guidance for Patients, Families, and the People Who Care for Them, by Thomas Moore (Hay House; 2010). The celebrated author of Care of the Soul laments the loss of humanistic values in our scientifically focused health care system. Moore's prescriptive vision for improving health care includes suggestions ranging from how to decorate waiting rooms to how to communicate with patients. But he also delves into esoteric notions like treating mouth sores with an awareness that "the mouth has memories of sucking the mother's breast." It's too bad he didn't stick to what he does best. — Lara Hazelton MD, Halifax, NS

Partner to the Poor: A Paul Farmer Reader, by Paul Farmer, edited by Haun Saussy (University of California Press; 2010). Dr. Paul Farmer, a cofounder of Partners in Health, has devoted his career to helping the poor gain access to medical services and treatment in Haiti, Rwanda, Peru, Mexico, Russia and elsewhere. This compilation of his essays and talks is thoughtprovoking and relevant to anyone interested in global health and issues related to its disparities. - Dennis Rosen MD, Boston, USA

The Emperor's New Drugs: Exploding the Antidepressant Myth, by Irvin Kirsch (Basic Books; 2010). Professor Irving Kirsch contends that "The belief that antidepressants can cure depression chemically is simply wrong." Kirsch does a credible job of defending this extreme and provocative statement, but in the end our reviewer found his arguments unconvincing. Daniel Carlat MD, Newburyport, USA

CMAJ 2011. DOI:10.1503/cmaj.110022

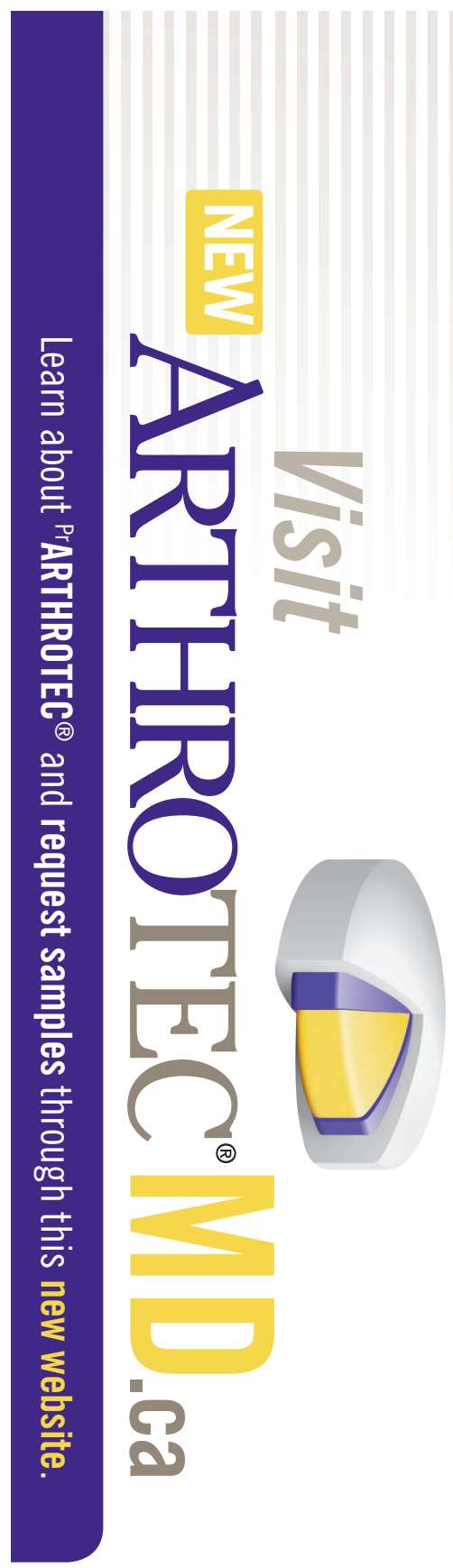

An NSAID with a mucosal protective agent, PrARTHROTEC ${ }^{\circledR}(50 \& 75 \mathrm{mg}$ diclofenac sodium and misoprostol tablets) has contraindications as well as warnings and precautions of use.

Please consult the Prescribing Information which is available on the ARTHROTECMD.ca website, or the Product Monograph which is available upon request.

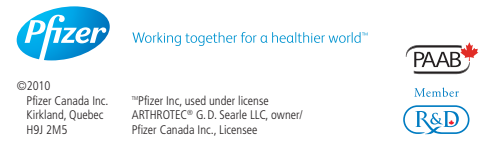

